\title{
PROCESO DE CONVENCIONALIZACIÓN DEL PRINCIPIO DE PRECAUCIÓN Y DE PREVENCIÓN EN EL MARCO DEL SISTEMA INTERAMERICANO: RETO Y PERSPECTIVA*
}

\author{
Process of conventionalized of the precaution and prevention \\ principle in the framework of the Inter-American System: challenge \\ and perspective
}

\author{
Anthony Castellanos Carreño** \\ David Castellanos Carreño*** \\ Corporación Universitaria Republicana. Bogotá D. C.
}

Recepción: 17 de abril de 2017. Aceptación: 21 de septiembre de 2017.

DOI: http://dx.doi.org/10.21017/Rev.Repub.2017.v23.a37

\section{RESUMEN}

El presente artículo analiza los principios de precaución y de prevención, tratados de manera conjunta por gran parte de la doctrina, en el contexto del sistema interamericano de protección y promoción de derechos humanos, especialmente, a la luz de los criterios de imputación de responsabilidad internacional que allí se utilizan. En este sentido, se muestra cómo hasta la fecha no se ha presentado un contexto jurídico, social y cultural que permita, a su vez, generar un pronunciamiento por parte del principal órgano contencioso de dicho sistema. Razón por la cual el artículo concluye que en el estado actual de las cosas no se puede hablar de un proceso de convencionalización de los mencionados principios, advirtiendo que esta puede llegar a cambiar a partir de la opinión consultiva planteada en el mes marzo del año 2016 por parte del Esta-

* Artículo producto de proceso de investigación, correspondiente al proyecto "Armonización del derecho internacional Público para el caso colombiano", adelantado en la línea de investigación "Derechos constitucionales fundamentales" del Grupo Derecho Público, adscrito al Centro de Investigaciones de la Corporación Universitaria Republicana.

** Magíster en Derecho Internacional Público de la Universidad de los Andes. Estudiante de doctorado, Universidad Libre. Docente investigador de la Corporación Universitaria Republicana. Correo electrónico: acastellanos@urepublicana.edu.co

*** Especialista en Derecho Administrativo de la Universidad Libre. Abogado de la Universidad Libre. Estudiante de maestría en "Derecho Privado, Persona y Sociedad con énfasis en Responsabilidad Contractual y Extracontractual Civil y del Estado", Universidad Externado de Colombia. Docente catedrático de la Facultad de Derecho de la Corporación Universitaria Republicana. Correo electrónico: davidcastellanos276@gmail.com 
do de Colombia y respecto de la responsabilidad ambiental que le asiste a los estados por el incumplimiento del deber de observancia y garantía de los referidos principios.

Palabras clave: responsabilidad, imputación, ambiente, convencionalización, principio de precaución, principio de prevención.

\begin{abstract}
Independently this article analyzes the principles of precaution and prevention, dealt with jointly by a large part of the doctrine, in the context of the interAmerican system for the protection and promotion of human rights, especially in light of the criteria of attribution International responsibility. In this sense, it is shown that to date there has not been a legal, social and cultural context that allows, in turn, to generate a ruling by the main contentious body of said system. Reason why the article concludes that in the current State of things we can not speak of a process of conventionalized ${ }^{1}$ of the aforementioned principles, noting that this trend may change from the advisory opinion raised in March of the year 2016 on the part of the State of Colombia and with respect to the environmental responsibility that assist the States for the breach of the duty of observance and guarantee of the mentioned principles.
\end{abstract}

Keywords: responsibility, imputation, environment, conventionalization, precautionary principle, prevention principle.

\title{
PREGUNTA PROBLEMA
}

El proceso de investigación adelantado para la elaboración del presente artículo se desarrolló en torno a la siguiente pregunta problémica: ¿La inobservancia del principio de precaución es constitutiva de responsabilidad internacional del Estado en el marco del SIDH?

1 The process of conventionalized refers to the control of conventionality that must be made between the internal legal rules applied by States in specific cases (domestic law) against the legal norms of the inter-American System of Human Rights. This name is used for the first time in the contentious case law of the Inter-American Court of Human Rights in the case of Almonacid Arellano v. Chile. Specifically, the process of conventionalized seeks to explain how the control of conventionality at the domestic level should be implemented for non-breach of internationally acquired obligations with the issuance or application of a specific internal norm, ie explains that national courts Not only should they be limited to carrying out a constitutional review of their decisions, but also of convention (American Convention of Human Rights). 


\section{RESULTADOS}

\section{Principio de Precaución}

El punto de partida para el análisis del principio de precaución, desde una perspectiva eminentemente etimológica, es el estudio de dos conceptos inescindibles entre sí: prae y cautio. El primero de ellos se encuentra situado en un ámbito temporal y debe ser entendido como un deber que impone advertir en el presente los efectos que una conducta u omisión pueda llegar a causar en el futuro. El segundo, por su parte, comprendido como el deber de adoptar medidas tendientes a evitar un resultado contrario a lo que podría esperarse en condiciones normales -elemento subjetivo-. Ambos, sin embargo, son de contenido obligacional (Córdoba, 2014) en términos del deber ser (Campbell, 2007).

En un ámbito jurídico, se puede decir que el principio de precaución encuentra su génesis en el derecho alemán (García, 2006) y, de alguna forma, en el ordenamiento jurídico francés del año 1995 -Ley Barnier- (Troncoso, 2010). Sin embargo, existen quienes atan el surgimiento al llamado Principio ALARA (As Low As Reasonably Achievable), adoptado en 1973 por la Comisión Internacional de Protección Radiológica; a la Conferencia de Estocolmo de 1972, sobre el Medio Ambiente Humano; a la Convención de Viena de 1985, sobre Protección de la Capa de Ozono (Yáñez, 2002), o a la Conferencia Internacional sobre la Protección del Mar del Norte de 1987.

En lo que a nosotros respecta, consideramos que el referido principio surge y se concreta en dos momentos diferentes: desde un punto de vista jurídicodogmático, en la década de los setenta en Alemania -Vorsorgeprinzip- y como una herramienta estatal para equilibrar el desarrollo empresarial en el campo teconógico y los efectos ambientales de dicho desarrollo después de transcurrido un largo tiempo y, desde un punto de vista jurídico-positivo, en la Declaración de Río de Janeiro sobre el Medio Ambiente y el Desarrollo del año 1992, específicamente en el Principio 15 que dice:

\footnotetext{
“Con el fin de proteger el medio ambiente, los Estados deberán aplicar ampliamente el criterio de precaución conforme a sus capacidades. Cuando haya peligro de daño grave o irreversible, la falta de certeza científica absoluta no deberá utilizarse como razón para postergar la adopción de medidas eficaces en función de los costos para impedir la degradación del medio ambiente.»
}

Sin perjuicio de lo anterior, debemos tener en cuenta que la formalización principialista de la precaución fue posterior a su consolidación como herramienta 
jurídico-dogmática. En efecto, como lo reconoce alguna parte de la doctrina (Troncoso, 2010), la precaución era una manera de actuar a priori y, sobre todo, una forma de actuar ex ante, y no una regla de contenido normativo que pudiera dar lugar a efectos jurídicos.

Como principio propiamente dicho, esto es, como una fuente normativa abstracta y de alcance indeterminado, la precaución requiere de un reconocimiento jurídico, que puede ser legal o jurisprudencial; en otras palabras, requiere del reconocimiento a partir de unos efectos particulares y concretos, como es el caso del artículo 5. ${ }^{\circ}$ de la Carta del Medio Ambiente de la Constitución Francesa, el conocido caso de las vacas locas (Mendizabal, 2014) y el artículo 1.6 de la Ley 99 de 1993, para el caso colombiano.

Con todo, debemos precisar que el campo de acción del principio de precuación no se restringe al ámbito de la protección del ambiente, pues, como se ha reconocido en algunos estados de la Comunidad Europea, el principio de precaución puede aplicarse a temas relacionados con salud y alimentación ${ }^{2}$, tal como se hizo en los casos Kellogs (Órgano de Vigilancia de la AELC/Noruega, 2001), Alfarma, Pfizer (García, 2006) y Virginiamicina (Vaqué), entre otros a los que nos referiremos más adelante.

El principio de precaución, por otra parte, tiene unos elementos que lo caracterizan y distinguen de otros principios e instituciones jurídicas. En efecto, para Troncoso (2010) el referido principio consta de dos elementos esenciales, a saber, la incertidumbre acerca de la existencia respecto de un riesgo de daño grave e irreversible y la obligación de adoptar medidas prematuras, proporcionadas y aptas para evitar el daño sospechado.

Por su parte Escalante (2005) asegura que los elementos esenciales del principio son la existencia de una amenaza de daño, que asocia con un peligro o riesgo, la incertidumbre científica de dicha situación de amenaza

2 Frente al particular, la profesora María Isabel Troncoso precisó: «La decisión más importante en el sector de la salud pública y la alimentación fue, sin duda, la concerniente al caso de las "vacas locas", que constituye en realidad la culminación de un proceso.

Existen varios ejemplos de casos en que los países de la Comunidad Europea empezaron a invocar el principio de forma implícita, en razón de la importación de productos alimenticios. En Alemania, por ejemplo, el gobierno lo invocó para prohibir la entrada de cerveza con "aditivos" (Ley alemana sobre la pureza de la cerveza) alegando que el efecto podía ser nocivo para salud. Una situación similar se presentó en Noruega, donde las autoridades gubernamentales rechazaron la entrada de cereales Kellogg's "enriquecidos con hierro", justificando la medida en la "necesidad de proteger la salud pública", dado que existía incertidumbre en relación con los efectos sanitarios de los alimentos fortificados.». Revista de Derecho Privado nro. 18, Universidad Externado de Colombia. Bogotá, 2010. 
y la obligación de gestionar acciones para prevenir el daño o, lo que es lo mismo, para proteger el bien en cuestión.

Para nosotros, el principio de precaución tiene dos elementos de su esencia: una incertidumbre calificada a nivel de sospecha y no de certeza propiamente dicha y la obligación especial de adoptar medidas para disminuir los daños causados indirectamente por la incertidumbre que se tiene frente a una situación en específico. El primero de ellos, creemos, debe apreciarse a partir del concepto de riesgo y de la naturaleza del daño que podría causarse o los bienes que resultaren comprometidos y el segundo, por su parte, envuelve la necesidad de verificar la idoneidad y efectividad de las medidas que se deben adoptar, entendiendo por efectividad la potencialidad de obtener el fin perseguido y por idoneidad la posibilidad de remediar la situación particular y concreta en una relación fáctica entre riesgo y prevención o causal entre prevención y daño.

Clément (2001) se refirió al particular en los siguientes términos:

«El centro de la obligación de prevención del sujeto se halla en la virtualidad de los distintos comportamientos para producir un daño y la necesidad de que el sujeto bajo cuya jurisdicción se realizan tales actos adopte las previsiones razonables, con una intensidad acorde a la magnitud de las fuerzas en juego, para evitar que de tales acciones pueda resultar daño a los legítimos intereses de otros sujetos de Derecho internacional. En este caso, hablamos de "obligación" de obrar de los sujetos, dado que hay certeza de que la acción entraña riesgos.»

\section{El Sistema Interamericano de Protección de los Derechos Humanos}

El principio de precaución, en el marco del Sistema Interamericano (en adelante SID), se utiliza como herramienta jurídica de interpretación de las obligaciones derivadas del Derecho Internacional Humanitario (en adelante DIH); en otras palabras, como una norma consuetudinaria para conflictos armados internacionales y no internacionales -Protocolos I y II de los Convenios de Ginebra-, pero no como un concepto del derecho ambiental y, mucho menos, como una norma aplicable a casos de salud o de consumo.

En efecto, la Corte Interamericana IDH (Masacre de Santo Domingo, 2012) precisó que el principio de precaución es una norma en la cual se establece que "[l]as operaciones [armadas] se realizarán con un cuidado constante de preservar a la población civil, a las personas civiles y los bienes de carácter civil»y, adicionalmente, que en virtud del mismo "[s]e tomarán todas las precauciones factibles para evitar o reducir en todo caso a un minimo, el 
número de muertos y heridos entre la población civil, así como los daños a bienes de carácter civil, que pudieran causar incidentalmente» (Caso masacre de Santo Domingo, 2012).

Sin embargo, en la doctrina del DIH -no en la Corte IDH- se ha distinguido entre el principio de precauciones en el ataque y el principio de precaución propiamente dicho (Louise Doswald-Beck, Jean-Marie Henckaerts, 2007). El primero, actualmente, está contenido en el artículo 57 del Protocolo Adicional I de los Convenios de Ginebra y es entendido como aquel que obliga a las partes de un conflicto a causar el menor daño posible en los ataques armados a la otra parte. El segundo, por su parte, apunta a que la falta de certeza científica frente a los efectos para el ambiente de determinadas operaciones militares no exime a las partes de tomar las debidas medidas de precaución para evitar daños injustificados, esto es, como el principio de precaución como tal (Louise Doswald-Beck, Jean-Marie Henckaerts, 2007).

Al referirse al particular, la Corte Internacional de Justicia (Armas Nucleares, 1996) señaló que el principio de precaución aplica para el empleo de armas en un conflicto armado (Barrera, 2010). En similares términos se pronunció el Comité Internacional de la Cruz Roja (Louise Doswald-Beck, JeanMarie Henckaerts, 2007) y, en general, los estudiosos del derecho internacional (Clément, 2003) y del derecho internacional humanitario (Bouvier, 1991).

Con todo, y aunque resulta evidente que la Corte IDH ha utilizado el principio de precaución restringiéndolo a la protección de los civiles en el contexto del $\mathrm{DIH}$, lo cierto es que no por eso puede decirse que dicho tribunal ha obviado la protección de los derechos ambientales, ya que, por el contrario, es de las cortes más activas en el tema.

En efecto, el tribunal interamericano se ha mostrado garante de los derechos relacionados con el medio ambiente, especialmente en los siguientes casos: (i) Mayagna Awas Tingni contra Nicaragua -2001-; (ii) Comunidad indígena Yakye Axa del pueblo Enxet-Lengua contra Paraguay -2005-; (iii) Comunidad indígena Sawhoyamaxa contra Paraguay -2006-; y, especialmente, (iv) Caso Claude Reyes y Otros contra Chile (Asociación Interamericana para la Defensa del Ambiente, 2008).

Allí, se ha condenado a los estados, primero, por el incumplimiento de su obligación de respeto de la propiedad colectiva de los pueblos indígenas, dándole un especial énfasis a la protección del ambiente y la relación de estos pueblos con la naturaleza y sus recursos y, segundo, el acceso a la información frente a un proyecto de deforestación. 
Como se observa, la protección interamericana que se ha dado al ambiente siempre ha sido indirecta, esto es, a través de otro derecho convencional, como la propiedad o el derecho de acceso a un recurso judicial efectivo y, en cierta medida, a la información. Sin embargo, esto se explica en el hecho de que el derecho a un ambiente sano se encuentra consagrado en el artículo 11 del Protocolo Adicional a la Convención Americana Sobre Derechos Humanos en materia de Derechos Económicos, Sociales y Culturales, «Protocolo de San Salvador», el cual, por disposición del artículo 19.6 ibídem, no resulta exigible judicialmente ante la Corte Interamericana de Derechos Humanos, es decir, porque se trata de un derecho de aquellos «no justiciables» de manera directa $\mathrm{y}$, por ende, que debe ser protegido por conducto de la diligencia que los estados deben tener en cuanto a la protección de otros derechos convencionales, esto es, a través de la debida diligencia como fundamento de responsabilidad estatal.

Puede decirse, hasta este momento, que en el SID la protección de los intereses ambientales no se ha dado en el marco del principio de precaución sino en el contexto de la debida diligencia, institución a la que nos referimos a continuación.

\section{Criterios para la determinación de la responsabilidad estatal}

El régimen jurídico de imputación de responsabilidad estatal, en lo que al SID respecta, difiere de los denominados regímenes subjetivos de responsabilidad estatal $^{3}$, ya que este último persigue la conducta de los agentes estatales, con miras a establecer algún tipo de «error»o «incumplimiento» para la imputación de unos perjuicios específicos, mientras que aquel tiene como objetivos principales la protección de las víctimas y la declaratoria de responsabilidad internacional del Estado, más allá de la calificación o reproche que pueda hacerse frente a la conducta del agente considerada de forma aislada o contextual. Lo dicho antes, claro está, sin que pueda, en forma alguna, llegarse al extremo de considerar que el mencionado régimen jurídico de imputación de responsabilidad es un régimen objetivo o que comparte sus características, expuestas en diferentes trabajos por la doctrina correspondiente (Quiñones \& Restrepo, 2014).

3 La Corte Interamericana de Derechos Humanos dijo en esa ocasión lo siguiente: «46. Por otro lado, es necesario tener presente que la protección internacional de los derechos humanos no debe confundirse con la justicia penal. En los casos en que los Estados comparecen ante el Tribunal no lo hacen como sujetos de un proceso penal. La función de la Corte no es imponer penas a los Estados o a las personas culpables de violar derechos humanos, sino proteger a las víctimas de tales violaciones, declarar internacionalmente responsables a los Estados por causa de estas, cuando haya lugar a ello, y ordenar a dichos Estados que reparen los daños ocasionados por los actos de que se trata [10]» (Negrillas fuera de texto). 
Consideramos importante resaltar que la responsabilidad internacional del Estado, además de ser diferente al régimen subjetivo de responsabilidad de sus agentes (Cantoral Venavides Vs. Perú, 2000), está supeditada a la existencia y demostración de un hecho ilícito (Báez, 2010), que bien puede darse por acción, por omisión de los agentes del Estado y, por conducto de estos últimos, por la conducta de un particular. El hecho internacionalmente ilícito, por su parte, requiere de la asunción previa de una obligación por parte del Estado -salvo en aquellos asuntos relaciondos con las denominadas normas ius cogens (art. 53 de la Convención de Viena de 1969)- y de la posibilidad de imputar el hecho ilítico en los términos del derecho internacional vigente.

Así las cosas, cuando la imputación de responsabilidad estatal se da por hechos atribuibles a la acción o conducta de un agente del Estado, resulta indispensable la demostración de las circunstancias fácticas del caso ${ }^{4} \mathrm{y}$, por supuesto, de los perjuicios causados como consecuencia de la consumación del hecho internacionalmente illícito.

Sin embargo, cuando el hecho internacionalmente ilícito proviene de una omisión, la concreción de la responsabilidad estatal resulta más compleja, especialmente porque lo relacionado con la prueba y con la imputación propiamente dicha adquiere una característica especial, esto es, involucra aterceros particulares en la concreción del daño, cualquiera que sea su naturaleza jurídica y particularidades concretas.

Surge así la siguiente pregunta: ¿Cómo imputarle responsabilidad internacional a un Estado cuando los perjuicios fueron causados por personas difentes a sus agentes? Y es que dicho interrogante adquiere mayor relevancia si se tiene en cuenta que, como se dijo en líneas anteriores, en el plano internacional no se juzga la conducta del agente en estricto sentido y, además, que lo que allí se juzga es la institucionalidad del Estado como tal, pero no los agentes que lo componen y que le sirven de alguna forma.

Para afrontar tales dificultades, la Corte Interamericana de Derechos Humanos ha acudido a tres criterios «jurisprudenciales» (Ardila, 2009), esto es: (i) la doctrina de la tolerancia, complicidad o aquiescencia de agentes del Estado; (ii) la dotrina de la "delegación" de los servicios inherentes a las funciones propias del Estado; (iii) y la doctrina del riesgo propiamente dicha -trae implícito el deber de debida diligencia-.

4 Es del caso precisar que la responsabilidad por «acción» puede derivarse de la violación de los derechos contenidos en la Convención Americana sobre Derechos Humanos y otros instrumentos «judicializables»-ratione materiae-, o por el incumplimiento del deber de adecuación de la legislación interna de los estados parte. 
Este último criterio también ha sido desarrollado en la Corte Internacional de Justicia, tal y como lo resalta Palafox (2008), en los siguientes términos:
"Como se podrá apreciar, tanto en el Caso Corfu Chanel como en el Caso de los Rehenes de la Embajada Estadounidense en Teherán, el control insuficiente por parte del Estado de los actos de terceros que afectaron los bienes y la seguridad de los extranjeros fundamentó una responsabilidad directa al Estado por la omisión de los órganos estatales. En ambos casos se pudo alegar que el Estado violó el criterio objetivo de debida diligencia, mismo que debía guardar para proteger los derechos de los extranjeros que se encontraban en su territorio. En todo caso, se reclamaba el deber de diligencia adecuada que deben guardar los Estados, y que es recono- cido por la comunidad internacional (...)».

La doctrina de la complicidad, tolerancia o aquiescencia, desde un punto de vista general, es un criterio que se ha utilizado en aquellos casos en los que se logra establecer que la violación de los derechos convencionales se materializó por el actuar de un tercero particular, pero con la complicidad ${ }^{5}$, la tolerancia ${ }^{6}$ o la aquiescencia ${ }^{7}$ de agentes del Estado. Esta hipótesis resultó apopiada para las «masacres colombianas».

La segunda, por su parte, ha resultado de aplicación excepcional ${ }^{8}$ y consiste, grosso modo, en que se responsabiliza al Estado por el perjuicio que causó el particular en ejercicio de una función que, en principio, le correspondía al Estado, pero que este «delegó» sin observar la vigilancia y control que le corresponden frente al particular.

La doctrina del riesgo, que resulta más importante por el objeto del presente escrito, y que fue traída del Sistema Europeo de Derechos Humanos (Abramovich, 2013), es aquella con fundamento en la cual se imputa responsabilidad estatal por hechos que si bien fueron perpetratos por particualres y sin la complicidad, tolerancia o aquiescencia del Estado, lo cierto es que pudieron ser evitados por este último a quien, para estos efectos, se le asigna un deber genérico de debida diligencia que, a su vez, trae implícita la obligación erga omnes de adoptar medidas positivas de protección y prevención de actos contrarios a los derechos protegidos convencionalmente.

5 En este sentido véase Caso La Rochela vs. Colombia (2007).

6 En este sentido véase Caso Mapiripán vs. Colombia (2005).

7 En este sentido véase Caso Blake vs. Guatemala (1998).

8 En este sentido véase Caso Ximenes Lopes vs. Brasil (2006). 
Con todo, resulta claro que el surgimiento de la responsabilidad internacional del Estado, en los casos en los que se acude al estándar de debida diligencia, está condicionado por el conocimiento previo de una situación de riesgo real e inmediato para un individio o un grupo de individuos determinado $\mathrm{y}$, sobre todo, a las posibilidades razonables de prevenir y evitar ese riesgo (Ardila), tal y como lo reconoció el Tribunal Europeo de Derechos Humanos (Caso Osman Vs. U. K., 1998) en los siguientes términos:

"For the Court, and bearing in mind the difficulties involved in policing modern societies, the unpredictability of human conduct and the operational choices which must be made in terms of priorities and resources, such an obligation must be interpreted in a way which does not impose an impossible or disproportionate burden on the authorities. [...] In the opinion of the Court where there is an allegation that the authorities have violated their positive obligation to protect the right to life [...] it must be established to its satisfaction that the authorities knew or ought to have known at the time of the existence of a real and immediate risk to the life of an identified individual or individuals from the criminal acts of a third party and that they failed to take measures within the scope of their powers which, judged reasonably, might have been expected to avoid that risk." 9

En este punto de la cuestión, debemos reiterar el hecho de que los criterios de imputación de responsabilidad internacional antes analizados, aun no han sido utilizados por la Corte IDH en casos ambientales o en procesos en los cuales se compromente el principio de precaución propiamente dicho -diferente al del DIH-, pues, como se dijo antes (supra II), el derecho a un ambiente sano no es judicializable, de forma directa, en el Sistema Intermericano de Derechos Humanos.

9 «Teniendo en cuenta las dificultades que implica la planificación y adopción de politicas públicas en las sociedades modernas, para la Corte, la impredictibilidad de la conducta humana y las opciones de carácter operativo que deben ser tomadas en función de las prioridades y los recursos disponibles, esa obligación positiva debe ser interpretada de forma que no imponga a las autoridades una carga imposible o desproporcionada. [...] En opinión de la Corte, cuando haya un alegato de que las autoridades han violado su obligación positiva de proteger el derecho a la vida [...], debe ser establecido con claridad que al momento de los hechos las autoridades sabian, o debian haber sabido, de la existencia de un riesgo real e inmediato para la vida de un individuo o individuos identificados de ser víctimas de actos criminales de terceros, y que tales autoridades no tomaron las medidas dentro del alcance de sus atribuciones que, apreciadas razonablemente, podían esperarse para evitar dicho riesgo». Traducido por la Secretaría de la Corte Interamericana de Derechos Humanos. 


\section{Debida diligencia}

La debida diligencia, como ya se dijo, es un criterio de imputación de responsabilidad internacional a los Estados por los perjuicios causados con sus omisiones; en otras palabras, se trata de una herramienta jurídica que sirve para declarar la responsabilidad de un Estado por hechos que, desde una perspectiva material, no le son imputables por no haber sido ocasionados por sus agentes «en sentido amplio».

Dicha herramienta "se manifiesta también en la obligación positiva del Estado de adoptar las medidas necesarias para asegurar la efectiva protección de los derechos en las relaciones entre los individuos» (Abramovich, 2013). Adicionalmente, la debida diligencia tiene como fundamento la doctrina del riesgo y este, a su vez, se circunscribe y está calificado por los elementos de i) certeza, entendiendo esta como todas aquellas cuestiones específicas o reales y no hipotéticas (Henao, 2007); ii) inmediatez, relacionada con la entidad temporal de concretarse; y iii) determinabilidad, asociada con la posibilidad de advertir los efectos directos o indirectos de la situación riesgosa.

Por otra parte, encontramos que la implementación de un deber de «debida diligencia» tiene como consecuencia directa la imposición a los estados de un estándar obligacional con fundamento en el cual se les conmina a adoptar medidas positivas.

Se trata, a nuestro juicio, de un estándar genérico o lato sensu y otro específico o estricto sensu, estando el primero compuesto por las obligaciones generales medidas positivas- de i) prevenir, ii) investigar y iii) sancionar (Abramovich, 2013), cuyo ámbito de aplicación se circunscribe a todos aquellos hechos de particulares -no agentes estatales- que puedan afectar derechos legal y convencionalmente protegidos.

El segundo, por su parte, es un estándar que varía dependiendo del tema en el que se aplique y, en especial, de las circunstancias particulares en que se determine o materialice. Dentro de este, por citar algunos ejemplos del SID, encontramos los estándares de protección de los pueblos indígenas (Masacre Plan Sánchez, 2004), de la población afrodescendiente (Simoné André Diniz vs. Brasil , 2006), las mujeres (Maria da Penha Maia Fernández vs. Brasil, 2001) y los niños (Niños de la Calle Vs. Guatemala, 1999), los cuales, como se dijo, varían en un caso y en otro en particular.

En lo que atañe al medio ambiente y a los derechos relacionados con la protección que se le da a este en el SID, como es el caso del agua (Humanos, 2007), el territorio (Comunidad Indígena Jakye Axa vs. Paraguay, 2005) y la vida 
(Comunidades Mayas del Distrito de Toledo vs. Belice, 2004), que, como se dijo en páginas anteriores, son derechos que se judicializan de manera directa ante la Corte IDH y dentro de los cuales, adicionalmente, encontramos «obligaciones» o criterios como "garantizar las condiciones mínimas de vida en el marco de concesiones de actividades económicas » (Comisión Interamericana de Derechos Humanos, 2007); "prevenir que las actividades extractivas comprometan las fuentes de agua potable" relacionada ésta con actividades como la pesca » (Pueblo Saramaka Vs. Surinam, 2007); la protección del ejercicio de prácticas culturales y ancestrales (Pueblo Saramaka Vs. Surinam, 2007) y la obligación general de proteger la subsistencia misma (Humanos, 2007).

Más recientemente (Pueblos Kaliña y Lokono vs. Surinam, 2015) se reconocieron en materia ambiental las obligaciones de los estados para i) proteger, ii) preservar y iii) mejorar el medio ambiente. En nuestro criterio, ese podría ser considerado el «estándar actual» de la debida diligencia en materia de la protección del medio ambiente, lo cual nos permitiría concluir que en esa materia las obligaciones de diligencia de los Estados están compuestas por los deberes genéricos de prevenir investigar y sancionar $\mathrm{y}$, además, por los deberes específicos de a) proteger, $\mathbf{b}$ ) preservar y c) mejorar el ambiente.

Sin perjuicio de lo dicho anteriomente, advertimos que no existe claridad suficiente en lo relacionado con el principio de precaución como parte del deber de debida diligencia en materia ambiental; primero, porque la Corte IDH no se ha referido a este de forma específica -sí lo ha hecho en casos de DIH- y, segundo, porque en la referida jurisprudencia no desarrolló el contenido de los deberes de proteger, preservar y mejorar el ambiente, es decir, no se fijaron parámetros que permitan establecer, por lo menos desde un punto de vista doctrinal, el contenido de dichos deberes y, con esto, indagar si los mismos contienen el principio de precaución para los casos ambientales.

Con todo, en esa misma decisión la Corte IDH también reconoció, implícitamente, el deber de los Estados de compatibilizar las obligaciones de proteger, preservar y mejorar el ambiente, con lo que ese tribunal denomina el amplio corpus iuris internacional, al cual también acudió para determinar el contenido obligacional del Estado en los casos citados en párrafos anteriores, esto es, indígenas, afrodescendientes, mujeres y niños.

En efecto, la Corte IDH en el caso Pueblos Kaliña y Lokono vs. Surinam, 2015 dijo:

«La Corte considera relevante hacer referencia a la necesidad de compatibilizar la protección de las áreas protegidas con el adecuado uso y goce de los territorios tradicionales de los pueblos indígenas. En este sentido, 
la Corte estima que un área protegida, consiste no solamente en la dimensión biológica, sino también en la sociocultural y que, por tanto, incorpora un enfoque interdisciplinario y participativo [216]. En este sentido, los pueblos indígenas, por lo general, pueden desempeñar un rol relevante en la conservación de la naturaleza [217], dado que ciertos usos tradicionales conllevan prácticas de sustentabilidad y se consideran fundamentales para la eficacia de las estrategias de conservación [218]. Por ello, el respeto de los derechos de los pueblos indígenas, puede redundar positivamente en la conservación del medio ambiente. Así, el derecho de los pueblos indígenas y las normas internacionales de medio ambiente deben comprenderse como derechos complementarios y no excluyentes [219]».

Dicha compatibilización, que, se insiste, consideramos implícita en el precedente citado, impone la necesidad-deber de interpretar la Convención Americana sobre Derechos Humanos y su Protocolo Adicional en materia de Derechos Económicos Sociales y Culturales a la luz de tratados internacionales como la Declaración de Río de Janeiro sobre el Medio Ambiente y el Desarrollo del año 1992, específicamente con el Principio 15 que contiene el principio de precaución como tal, entre otros instrumentos internacionales bien compilados por Escalante (2005).

Se debe advertir que Colombia, en buena hora, elevó consulta ${ }^{10}$ a la Corte Interamericana de Derechos Humanos, en la que le pidió pronunciarse de fondo, entre otros aspectos, sobre el contenido de los deberes de respeto y garantía frente a las normas del derecho internacional que provienen del medio ambiente, en lo relacionado con la construcción de grandes obras de infraestructura en la Región del Gran Caribe.

A nuestro juicio, en la correspondiente Opinión Consultiva se aclarará si el principio de precaución hace parte del deber de debida diligencia y, como tal, si es posible responsabilizar a un Estado internacionalmente por la inobservancia de dicho principio.

Por ahora, se tiene que, por el estado actual del precedente interamericano, el riesgo sigue siendo el elemento principal del deber-diligencia y, como tal, que

10 Dicha consulta se elevó con fundamento en el artículo 64.1 de la Convención Americana sobre Derechos Humanos, que dispone que: «1. Los Estados miembros de la Organización podrán consultar a la Corte acerca de la interpretación de esta Convención o de otros tratados concernientes a la protección de los derechos humanos en los Estados americanos. Asimismo, podrán consultarla, en lo que les compete, los órganos enumerados en el capítulo X de la Carta de la Organización de los Estados Americanos, reformada por el Protocolo de Buenos Aires.». 
el contenido obligacional del Estado se encuentra supeditado por dicho concepto, en el sentido de que se hace necesaria la existencia de una situación particular de riesgo para que los Estados se obliguen a actuar con debida diligencia -en sentido lato y estricto-.

Finalmente, se debe precisar que para algunos autores (Clément, 2001), la debida diligencia es el mismo principio de prevención. Sin embargo, consideramos que no se trata de conceptos sinónimos sino de conceptos que dependen el uno del otro en una relación de especie a género, siendo la debida diligencia el género y la prevención la especie, pero que no obedecen a la misma lógica, como se verá a continuación.

\section{Principios de precaución y prevención}

El principio de prevención ${ }^{11}$, para los efectos del presente escrito, lo entendemos como un mandato de optimización (Mesa, 2004) que impone al Estado un estándar mínimo de protección de los derechos subjetivos y, especialmente, que le impone obligaciones para prevenir la materialización de hechos que puedan afectar en forma alguna intereses de índole ambiental.

Además, como se dijo anteriormente (supra iv), en compañía de los deberes de investigación y sanción, es uno de los componentes del estándar genérico de debida diligencia; en otras palabras, que se trata de uno de los elementos necesarios para la determinación del hecho internacionalmente ilícito y, en consecuencia, para la configuración de responsabilidad internacional de los Estados, en lo que tiene que ver con las conductas que se le imputan a título de omisión (supra iii).

Sin embargo, para los fines del presente escrito, resulta indispensable distinguirlo del principio de precaución, ya que dicha distinción será la que nos permita arribar a las conclusiones finales y, sobre todo, será el punto de partida para lo que se pretende exponer a título de hipótesis mediante las líneas antes plasmadas.

En efecto, se trata de dos principios con grandes diferencias marcadas, pero con un factor común, esto es, el riesgo, pues si bien es cierto que en uno y otro caso la «calificación» que dicho concepto recibe es distinta, también lo que es

11 Suele sostenerse que dicho principio tiene como origen, de una parte, los artículos principios- 2, 4 y 7 de la Declaración de las Naciones Unidas sobre el Medio Humano Estocolmo, el 16 de junio de 1972- y, de la otra, el artículo 130-P-2) del Tratado de Maastricht. 
en ambos casos lo que se analiza es el factor de riesgo frente a una actividad determinada y específica.

Con fundamento en Clément (2001) podemos afirmar que dichos principios, en lo que atañe a la responsabilidad internacional de los Estados, se diferencian con fundamento en lo siguiente:

(i) El principio de prevención parte del concepto de debida diligencia, entendida esta como obligaciones dirigidas a los sujetos del derecho internacional, especialmente a los Estados, para que garanticen un estándar mínimo de protección de los derechos subjetivos, mientras que el principio de precaución tiene como fundamento el concepto de gestión ${ }^{12} \mathrm{y}$, sobre todo, aquella que se adelanta para limitar una actividad que se considera riesgosa;

(ii) El riesgo, para el caso del principio de prevención, debe ser cierto, mientras que en lo referente al principio de precaución, el mismo debe ser dudoso, pero nunca inexistente;

(iii) El principio de prevención impone un contenido obligacional a quien tiene la obligación de evitar el resultado negativo, pero el de precaución se adecúa más al concepto de conveniencia y, como tal, de este último no puede predicarse un contenido obligacional específico; y

(iv) Para imputar responsabilidad internacional a un Estado por la inobservancia del principio de prevención, es necesario que se hubiera sufrido un daño o que exista un riesgo cierto de sufrirlo, pero en el caso del principio de precaución se imputa a partir de unos eventos determinados, como pueden ser, a manera de ejemplo: a) que la parte obligada a aplicar dicho principio actúe sin sustentarse en criterios de razonabilidad suficiente; b) que se hubiera negado a revisar las medidas a la luz de los distintos criterios de certidumbreincertidumbre de índole científicos; y c) que la adopción de medidas precautorias impliqe una forma de proteccionismo.

El Consejo de Estado (Diego Domínguez vs. C. V. C., 2015), por su parte, entiende que la diferencia entre uno y otro radica en la evidencia frente a la certeza de los riesgos y la probabilidad de ocurrencia del daño que pretenda evitarse, ya que el principio de prevención supone un riesgo que puede ser conocido anticipadamente y, como tal, que pueden adoptarse medidas para «neutralizarlo», mientras que en sede del principio de precaución el riesgo no

12 Para la autora el concepto apropiado es «buen gobierno». Sin embargo, también acepta el término gestión. 
puede ser conocido anticipadamente y, en consecuencia, sus efectos no pueden ser conocidos a mediano y largo plazo.

En efecto, el Consejo de Estado (Diego Dominguez Vs. C.V.C., 2015), al referirse al tema, dijo:

«Empero, el previo conocimiento que caracteriza al ámbito de operatividad del principio de prevención, no está presente en el entramado de casos gobernados por el principio de precaución o de cautela, pues tratándose de este el riesgo o la magnitud del daño producido o que puede sobrevenir no son conocidos con anticipación, toda vez que no se dispone de la posibilidad fáctica real de establecer, a mediano o largo plazo, los efectos de una acción, circunstancia que obedece a la falta de evolución al respecto en el conocimiento científico, desde el cual puede no resultar posible alcanzar la certeza en punto de las precisas consecuencias que acarrearía alguna situación o actividad, así se conozca que tales efectos serán nocivos.»

A nuestro juicio, la diferencia entre los mencionados principios radica en el grado de certeza que pueda tenerse en lo relacionado con el riesgo, de tal manera que, existiendo un grado de certeza o certidumbre, así sea mínimo, deben aplicarse medidas preventivas -principio de prevención-, pero si no existe tal certeza o certidumbre lo procedente son medidas precautorias o de cautela -principio de precaución-.

Tal distinción, a nuestro juicio, resulta apropiada si se tiene en cuenta que la determinación de responsabilidad internacional del Estado en los casos de daños ambientales causados por terceros, en el estado actual del precedente interamericano, está circunscrita a la existencia de un riesgo cierto y materialmente evitable, esto es, a la certeza frente en la relación riesgo-daño.

\section{CONCLUSIONES}

El principio de precaución en materia ambiental no ha sido abordado por la Corte Interamericana de Derechos Humanos y, en consecuencia, no podemos hablar de un proceso de convencionalización en estricto sentido.

Esto no quiere decir que dicho principio no sea exigible en el ordenamiento jurídico colombiano, primero, porque legalmente ya fue desarrollado y, segundo, porque el mismo, según el precedente de la Corte Constitucional C703 del 2010- se encuentra constitucionalizado porque se desprende de lo que dicho tribunal denomina «internacionalización de las relaciones ecológicas». 
En el SID el principio de precaución encuentra aplicación en relación con las normas del derecho internacional humanitario y de las garantías que puedan tener relación con este.

Lo anterior no excluye la posibilidad-necesidad de que la Corte Interamericana de Derechos Humanos pueda llegar a regularlo de forma expresa y formal, lo cual esperamos que llegue a hacer al responder la opinión consultiva que Colombia presentó en marzo del año 2016.

Nos aventuramos, a nivel de hipótesis, a afirmar que el referido tribunal internacional incluirá dentro del concepto de debida diligencia que nosotros llamamos estricto sensu o específico, acompañándolo de los ya mencionados deberes de proteger, preservar y mejorar el ambiente (Pueblos Kaliña y Lokono vs. Surinam, 2015), pues las pautas están sentadas para ello y, además, dogmáticamente es viable que a un Estado se le responsabilice por los perjuicios causados por el incumplimiento del deber de precaución, siempre que se logre demostrar dentro del proceso que este tenía el deber de actuar y no lo hizo adecuadamente.

Adicionalmente, consideramos, también como hipótesis, que el principio de precaución puede introducirse en el SID, por una parte, a través de la obligación de compatibilización que la Corte Interamericana dejó abierta (Pueblos Kaliña y Lokono vs. Surinam, 2015) y, por la otra, por conducto del concepto de corpus iuris internacional que maneja ese tribunal.

En todo caso, la condena que se imponga a un Estado por su falta al deber de precaución en materia ambiental, siempre estará ligada a derechos convencionales distintos del medio ambiente, pues dicha garantía, por disposición expresa del Protocolo de San Salvador, no es judicializable ante la Corte Interamericana de Derechos Humanos -ratione materia-

\section{REFERENCIAS}

Abramovich, V. (6 de marzo de 2013). Responsabilidad estatal por violencia de género: comentarios sobre el caso «Campo Algodonero» en la Corte Interamericana de Derechos Humanos. Obtenido de Corte Interamericana de Derechos Humanos: http:// www.corteidh.or.cr/tablas/r31644.pdf

Ardila, F. M. (2009). La responsabilidad internacional del Estado por actos de particulares: análisis jurisprudencial interamericano. Obtenido de Corte Interamericana de Derechos Humanos: http://www.corteidh.or.cr/tablas/r26724.pdf 
Armas nucleares (Corte Internacional de Justicia, 8 de julio de 1996).

Asociación Interamericana para la Defensa del Ambiente. (enero de 2008). Asociación Interamericana para la Defensa del Ambiente. Obtenido de Guía de Defensa Ambiental: http://www.corteidh.or.cr/tablas/24756.pdf

Báez, J. J. (2010). La Jurisprudencia de la Corte Interamericana de Derechos Humanos en Materia de Reparaciones y los Criterios del Proyecto de Artículos sobre Responsibilidad del Estado por Hechos Internacionalmente Ilícitos. American University International Law Review Vol. 23, nro. 1, 91-126.

Barrera, H. M. (2010). La protección del medio ambiente en período de conflicto armado. Ciencia en su PC nro. 4, 89-102.

Bouvier, A. (1991). La protección del medio ambiente en período de conflicto armado. Revista Internacional de la Cruz Roja.

Campbell, Y. (2007). Del ser al deber ser. Teatro de Palabras, 29-45.

Cantoral Venavides vs. Perú, Serie C_69 (Corte Interamericana de Derechos Humanos, 18 de agosto de 2000).

Caso Osman vs. U.K., Osman vs. United Kingdom (Corte Europea de Derechos Humanos, 28 de octubre de 1998).

Clément, Z. D. (2001). los principios de prevención y precaución en materia ambiental en el sistema internacional y en el interamericano. Jornadas de Derecho Internacional OEA, 81-92.

Clément, Z. D. (2003). El daño deliberado y substancial al medio ambiente, como objetivo, medio o método de guerra constituye violación de norma imperativa de derecho internacional general. Derecho internacional humanitario y temas de áreas vinculadas nro. 78, 265-296.

Comisión Interamericana de Derechos Humanos. (28 de junio de 2007). Comisión Interamericana de Derechos Humanos. Obtenido de http://www.cidh.org/ pdf\%20files/BOLIVIA.07.ESP.pdf

Comunidad Indígena Jakye Axa vs. Paraguay (Corte Interamericana de Derechos Humanos, 17 de junio de 2005).

Comunidades Mayas del Distrito de Toledo vs. Belice (Comisión Interamericana de Derechos Humanos, 12 de octubre de 2004). 
Córdoba, J. I. (2014). Falla del servicio por omisión al contenido obligacional que engendra el principio de prevención. Responsabilidad extracontractual del Estado por daño ambiental. Bogotá: Universidad Externado.

Diego Domínguez vs. C. V. C., 37603 (Consejo de Estado, 4 de noviembre de 2015).

Escalante, J. M. (2005). Principio de Precaución y Medio Ambiente. Revista Especial Salud Pública nro. 2, 133-144.

García, A. C. (2006). Algunas consideraciones sobre el principio de precaución como instrumento de protección de la salud de los consumidores en el ámbito alimentario. Centro de Estudios de Consumo, 1-19.

García, A. C. (2006). Estudio sobre la aplicación del principio de precaución por el tribunal de justicia de las comunidades europeas . Obtenido de Universidad de Castilla la Mancha: https://www.uclm.es/centro/cesco/pdf/trabajos/19/2006/19-2006-2.pdf

Henao, J. C. (2007). El daño. Bogotá: Universidad Externado de Colombia.

Humanos, C. I. (29 de diciembre de 2007). Comisión Interamericana de Derechos Humanos. Obtenido de Comisión Interamericana de Derechos Humanos: https:// www.cidh.oas.org/annualrep/2007sp/indice2007.htm

Louise Doswald-Beck, Jean-Marie Henckaerts. (2007). El derecho Internacional Humanitario Consuestudinario. Volumen I: Normas. Buenos Aires: Comité internacional de la Cruz Roja.

Maria da Penha Maia Fernández Vs. Brasil (Comisión Interamericana de Derechos Humanos, 16 de abril de 2001).

Masacre de Santo Domingo, Serie C_259 (Corte IDH, 30 de noviembre de 2012).

Masacre Plan Sánchez (Corte Interamericana de Derechos Humanos, 29 de abril de 2004).

Mendizabal, V. (2014). Aula Bioforum. Obtenido de Bioforum Argentina: https:// bioforumargentina.files.wordpress.com/2014/11/la-crisis-de-las-vacas-locas.pdf

Mesa, G. P. (2004). Los derechos fundamentales como mandatos de optimización. Doxa - Cuadernos de filosofía del derecho nro. 27, 211-243.

Niños de la Calle vs. Guatemala (Corte Interamericana de Derechos Humanos, 19 de noviembre de 1999). 

prevención en el marco del Sistema Interamericano: reto y perspectiva

Órgano de Vigilancia de la AELC/Noruega, Caso Kellogg's (Tribunal de la AELC, 5 de abril de 2001).

Palafox, F. I. (2008). Jurisprudencia sobre la responsabilidad internacional del Estado por omisión. Refelxiones a partir del caso de los homicidios y desapariciones de mujeres y niñas y Ciudad Juárez, Chihuahua. Obtenido de Miguel Carbonell: http:// www.miguelcarbonell.com/artman/uploads/1/jurisprudencia_sobre.pdf

Pueblo Saramaka vs. Surinam (Corte Interamericana de Derechos Humanos, 28 de noviembre de 2007).

Pueblos Kaliña y Lokono vs. Surinam (Corte Interamericana de Derechos Humanos, 25 de noviembre de 2015).

Quintero, H.S. (s. f.). Falla del servicio por omisión al contenido obligacional que engendra el principio de prevención. Bogotá.

Quiñones, S. R., \& Restrepo, J. D. (2014). De la causalidad adecuada a la imputación objetiva en la responsabilidad civil. Vuniversitas nro. 129, 187-235.

Simoné André Diniz vs. Brasil (Comisión Interamericana de Derechos Humanos, 21 de octubre de 2006).

Troncoso, M. I. (2010). El principio de precaución y la responsabilidad civil. Revista de Derecho Privado nro. 18, 205-220.

Vaqué, L. G. (s.f.). El principio de precaución en la jurisprudencia comunitaria: la sentencia «virginiamicina» (Asunto T-13/99). 925-942.

Yáñez, G. F. (2002). El principio de precaución frente a los viejos conceptos de la responsabilidad civil. El principio de precaución frente a los viejos conceptos de la responsabilidad civil, (pág. 9). Bilbao, España. 